\title{
FUEL-CYCLE SCENARIO TO REDUCE RADIOACTIVE WASTE FROM LIGHT-WATER REACTOR
}

\author{
Satoshi Wada ${ }^{1}$, Kouji Hiraiwa ${ }^{2}$, Kenichi Yoshioka ${ }^{1}$, Tsukasa Sugita ${ }^{1}$, and Rei Kimura ${ }^{1}$ \\ ${ }^{1}$ Toshiba Energy Systems \& Solutions Corporation \\ 4-1 Ukishima-cho, Kawasaki-ku, Kawasaki 210-0862, Japan \\ ${ }^{2}$ Toshiba Energy Systems \& Solutions Corporation \\ 8 Shinsugita-cho, Isogo-ku, Yokohama 235-8523, Japan \\ satoshi9.wada@toshiba.co.jp,kouji.hiraiwa@toshiba.co.jp, kenichi.yoshioka@toshiba.co.jp \\ tsukasa.sugita@toshiba.co.jp,rei.kimura@toshiba.co.jp
}

\begin{abstract}
It is important to reduce the amount of trans-uranium (TRU) produced from the existing nuclear power plants to realize sustainable nuclear energy since the some TRU nuclides remain for a long time and have high radioactivity and radiotoxicity. One of the promising solutions is to transmute the TRU nuclides to those with lesser radioactivity and radiotoxicity in the existing nuclear reactors. In the current scheme, the TRU nuclides are transmuted in fast reactors and/or accelerator-driven-systems, however, this scenario seems unpromising in Japan: after the Fukushima Daiichi accident, it is required to reduce the production of TRU nuclides from the light-water reactors. In the previous studies, a concept of FORSETI was investigated, and a nuclear-fuel cycle simulation code ATRUNCYS was developed to study the low TRU production scenario. The FORSETI concept consists of two types of fuels: 1) $\mathrm{UO}_{2}$ fuels with high-assay low-enriched-uranium, and 2) MOX fuels with highly fissile concentrated plutonium reprocessed from the FORSETI-UO $\mathrm{U}_{2}$ fuels. The current paper focuses on the following two scenarios: a) once-recycled scenario with the current fuel design, and b) once-recycled scenario with the FORSETI concept. The two scenarios were compared by using the ATRUNCYS code where the simulation studies showed that the amount, radioactivity, and radiotoxicity of resulting waste can be decreased in the FORSETI concept: In the case 1), the production of TRU nuclides decreased in the $\mathrm{UO}_{2}$ fuel; In the case 2), the fission rate increased and neutron-capture reactions of ${ }^{240} \mathrm{Pu}$ and ${ }^{241} \mathrm{Pu}$ decreased in the MOX fuels.
\end{abstract}

KEYWORDS: Nuclear-fuel cycle, Light-water reactor, Trans-uranium, FORSETI

\section{INTRODUCTION}

Nuclear energy provides stable electricity as a low-carbon base-load power source (Ref. 1). There is a recent global trend to shift to the sustainable, economical and safe energy sources. In the case of nuclear energy, highly safe systems that produce lesser nuclear waste are required for the nuclear fuel cycle. To reduce the amount of nuclear waste in the nuclear-fuel cycle, it is important to reduce fission products (FPs) and transuranium nuclides (TRU) which have a high heating fraction flux, radioactivity and radiotoxicity for a long period of time as shown in Figure 1. Reducing the long-lived nuclides with high radiotoxicity is important 
for a radioactive-waste management (Ref. 2), however, it is not realistic to control the amount of produced FPs that have high radioactivity for 100 years in nuclear power plants (NPPs), because fission yield could not be changed to reduce environmental loading. Therefore, accelerator driven systems have been discussed as a promising plan to reduce FPs. On the other hand, NPPs can transmute TRU nuclides, but cannot control the TRU production themselves. In general, fast reactors (FRs) and/or accelerator-driven-systems (ADSs) (Ref. 3) are considered to transmute TRU nuclides from light-water reactors (LWRs), however, the scenario has been suspended in Japan. Also, the ADSs are still in the feasibility study stage (Ref. 4). In Japan, use of the mixed-oxide (MOX) fuels in the LWRs is planned from the viewpoints of nuclear security and the reduction of high-level radioactive waste. Under these circumstances, reducing TRU nuclides in the LWRs has become the primary issue for the nuclear fuel cycle.

In our previous studies, conceptual studies of FORSETI, Fuel cycle of light-water reactor with surplus enriched uranium for TRU-production inhibition were made (Ref. 5, 6). In the FORSETI concept, the TRU production decreases by using uranium-dioxide $\left(\mathrm{UO}_{2}\right)$ fuels with high-assay low-enriched-uranium (HALEU) and MOX fuels with high ${ }^{239} \mathrm{Pu}$-to-total-plutonium-ratio $\mathrm{Pu}$ reprocessed from FORSETI-UO ${ }_{2}$ fuels. In addition, a nuclear-fuel cycle simulation code ATRUNCYS, Advanced TRU Nuclear Cycle

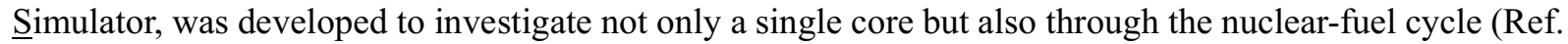
7 ). In the current paper, the nuclear-fuel cycle scenario using FORSETI concept is investigated and fuel cycle parameters that have impact to the TRU scenario are discussed.

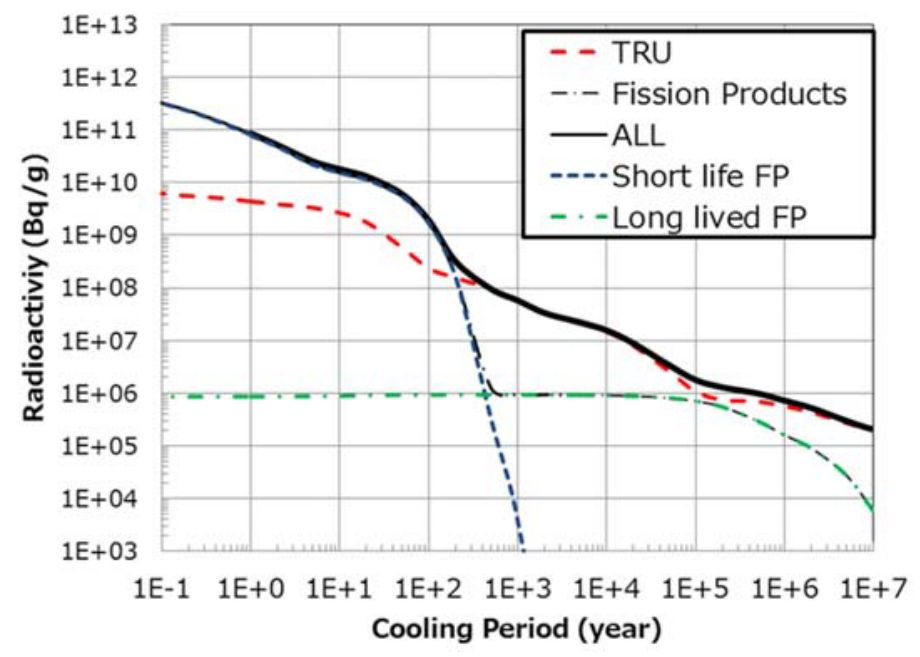

Figure 1. Radioactivity of spent-UO $\mathrm{O}_{2}$ fuel from LWR (Ref. 6).

\section{CONCEPT OF FUEL-CYCLE SCENARIO}

\subsection{Production path of high radioactivity and radiotoxicity TRU}

The highly radioactive and radiotoxic TRU from LWRs are ${ }^{238} \mathrm{Pu},{ }^{239} \mathrm{Pu},{ }^{240} \mathrm{Pu},{ }^{241} \mathrm{Pu},{ }^{241} \mathrm{Am},{ }^{242} \mathrm{Cm}$, and ${ }^{244} \mathrm{Cm}$. These nuclides are the results of neutron-capture reactions and beta-decays, as shown in Figure 2 . The TRU production can be reduced by reducing neutron-capture reactions of neptunium, plutonium, and minor actinides. 


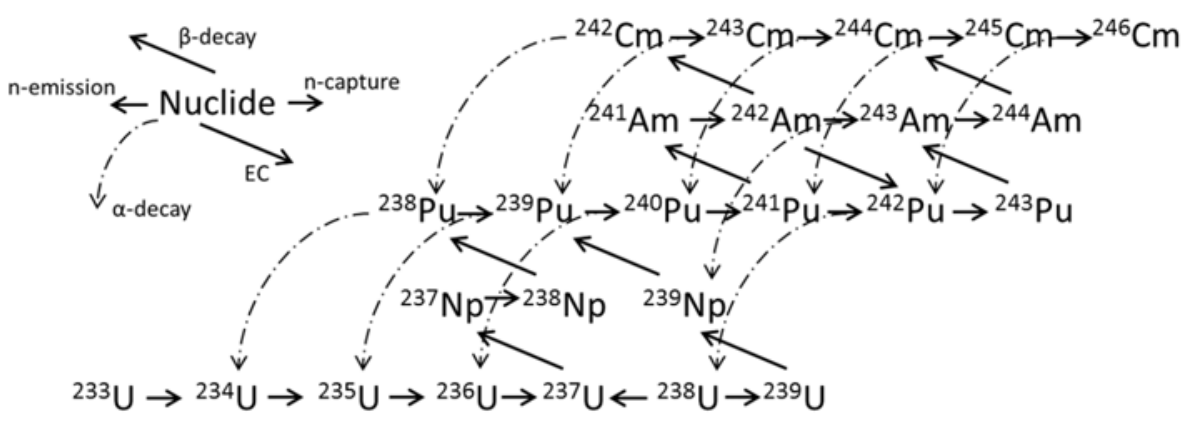

Figure 2. Burnup chain (Ref. 6).

\subsection{FORSETI concept}

To reduce the production of TRU, it is necessary to increase fission rate or to reduce capture rate and betadecays. In FRs, fission rate can be increased and capture rate can be reduced by taking advantage of fast neutrons. On the other hand, neutrons are thermalized in the case of LWRs, therefore, it is important to increase fission rate of fissile nuclides to reduce capture reactions.

In the case of $\mathrm{UO}_{2}$ fuel, fissile nuclide composition can be increased by increasing uranium enrichment i.e. HALEU. In the case of MOX fuel, enriched uranium or using Pu with increased ${ }^{239} \mathrm{Pu}$ composition can be used for the base material to provide the same effect. To satisfy these two conditions, the concept of FORSETI has the following six steps as shown in Figure 3:

- Use $\mathrm{UO}_{2}$ fuels with HALEU in the LWR,

- Discharge the $\mathrm{UO}_{2}$ fuels before burned out,

- Reprocess the spent- $\mathrm{UO}_{2}$ fuels and extract $\mathrm{Pu}$ with high ${ }^{239} \mathrm{Pu}$ composition ratio,

- Fabricate MOX fuels with the reprocessed $\mathrm{Pu}$,

- Use the MOX fuels in the LWR,

- Multi-recycle the MOX fuels.

The following effects are expected by using the FORSETI concept,

1. In the case of $\mathrm{UO}_{2}$ core, a fraction of thermal neutrons becomes smaller by increasing uranium enrichment under the same power density, therefore, capture-reactions of plutonium becomes less and the TRU production is decreased, and

2. In the case of MOX core, composition of the Pu can be reduced since the Pu that reprocessed FORSETI$\mathrm{UO}_{2}$ contains more ${ }^{239} \mathrm{Pu}$ than usual, therefore, capture-reactions of plutonium becomes less and the TRU production is decreased.

The FORSETI concept has a high affinity with the nuclear-fuel cycle including FRs, because the composition rate of Pu becomes better than the current spent-fuels from LWRs. 


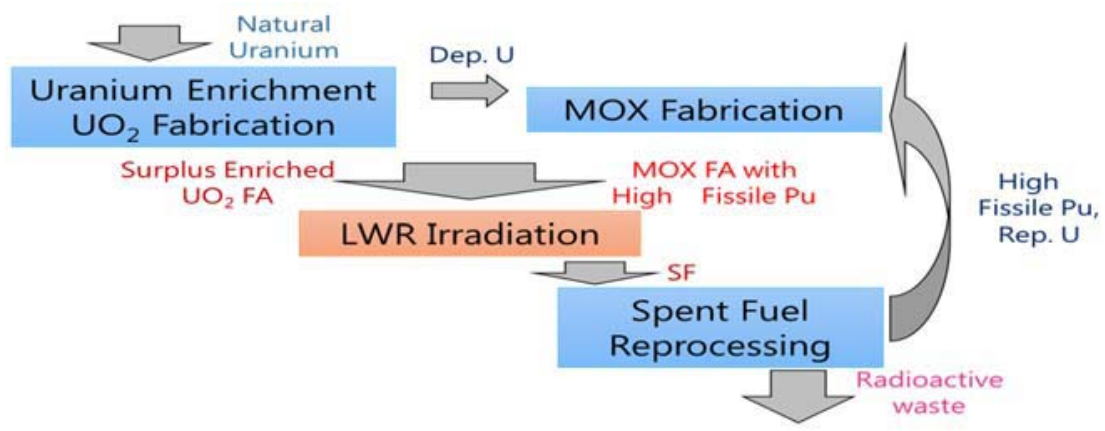

Figure 3. Material flow of FORSETI.

\section{SIMULATION OF FUEL-CYCLE SCENARIO}

ATRUNSYS code was used to investigate the once-recycled fuel-cycle scenario with the FORSETI concept. The ATRUNCYS code can simulate mass balance, radioactivity, radiotoxicity and radio-heating fraction in various fuel-cycle scenarios by using decay matrix and burn-up tables prepared in advance. In the current paper, the decay matrix was obtained by ORIGEN-2 (Ref. 8) with ORLIBJ40 (Ref. 9) and the burn-up table of each core-type was obtained by MVP-BURN (Ref. 10) with JENDL-4.0 (Ref. 11).

\subsection{Fuel-cycle scenario}

The fuel parameters of each fuel-cycle scenario are summarized in Table I. These parameters are based on the current BWR plant design and used same parameters in each case. The minimum cooling time was based on the current situation of the reprocessing plant in Japan (Ref. 12). The initial composition rate of each bundle is summarized in Table II. The initial Pu stocks are not considered. The installed electric power capacity of each scenario is shown in Figure 4: the electric power capacity of MOX core increases for 5 years from 2033. In the scenario using the FORSETI concept, the electric capacity caused by MOX fuel is larger than that in the current scenario. FORSETI-UO ${ }_{2}$ produces $\mathrm{Pu}$ with increased ${ }^{239} \mathrm{Pu}$ composition, therefore, Pu-enrichment of FORSETI-MOX can be decreased and the fabrication capacity of MOX fuels can be increased. The reprocessed uranium was supposed not to be re-enriched and re-used in the next $\mathrm{UO}_{2}$ fuels. In the present study, upper limit of total reprocessing capacity was not decided and the reprocessing plant is operated depend on the demand from MOX cores.

Table I. Fuel cycle parameters.

\begin{tabular}{|c|c|c|c|c|}
\hline \multirow{2}{*}{ Parameter } & \multicolumn{2}{|c|}{ Current } & \multicolumn{2}{c|}{ FORSETI } \\
\cline { 2 - 5 } & $\mathrm{UO}_{2}$ & $\mathrm{MOX}$ & $\mathrm{UO}_{2}$ & $\mathrm{MOX}$ \\
\hline EFPM $^{*}[\mathrm{month}]$ & 15.0 & 15.0 & 15.0 & 15.0 \\
\hline Discharge exposure [GWd/tHM] & 45.0 & 45.0 & 45.0 & 45.0 \\
\hline Thermal Power [MWt] & 3,900 & 3,900 & 3,900 & 3,900 \\
\hline Power density [kW/1] & 50 & 50 & 50 & 50 \\
\hline Fabrication time [year] & 2 & 2 & 2 & 2 \\
\hline Minimum cooling time [year] & 15 & 15 & 15 & 15 \\
\hline
\end{tabular}

\footnotetext{
${ }^{*}$ : Effective full power month
} 
Table II. Bundle-averaged initial composition rate [wt\%].

\begin{tabular}{|c|c|c|c|c|}
\hline \multirow{2}{*}{ Nuclide } & \multicolumn{2}{|c|}{ Current } & \multicolumn{2}{c|}{ FORSETI } \\
\cline { 2 - 5 } & $\mathrm{UO}_{2}$ & $\mathrm{MOX}$ & $\mathrm{UO}_{2}$ & $\mathrm{MOX}$ \\
\hline${ }^{235} \mathrm{U}$ & 3.9 & 1.2 & 9.0 & 1.2 \\
\hline${ }^{238} \mathrm{U}$ & 96.1 & 91.9 & 91.0 & 94.7 \\
\hline${ }^{238} \mathrm{Pu}$ & - & 0.2 & - & 0.1 \\
\hline${ }^{239} \mathrm{Pu}$ & - & 3.6 & - & 2.9 \\
\hline${ }^{240} \mathrm{Pu}$ & - & 2.1 & - & 0.8 \\
\hline${ }^{241} \mathrm{Pu}$ & - & 0.4 & - & 0.2 \\
\hline${ }^{242} \mathrm{Pu}$ & - & 0.6 & - & 0.1 \\
\hline
\end{tabular}
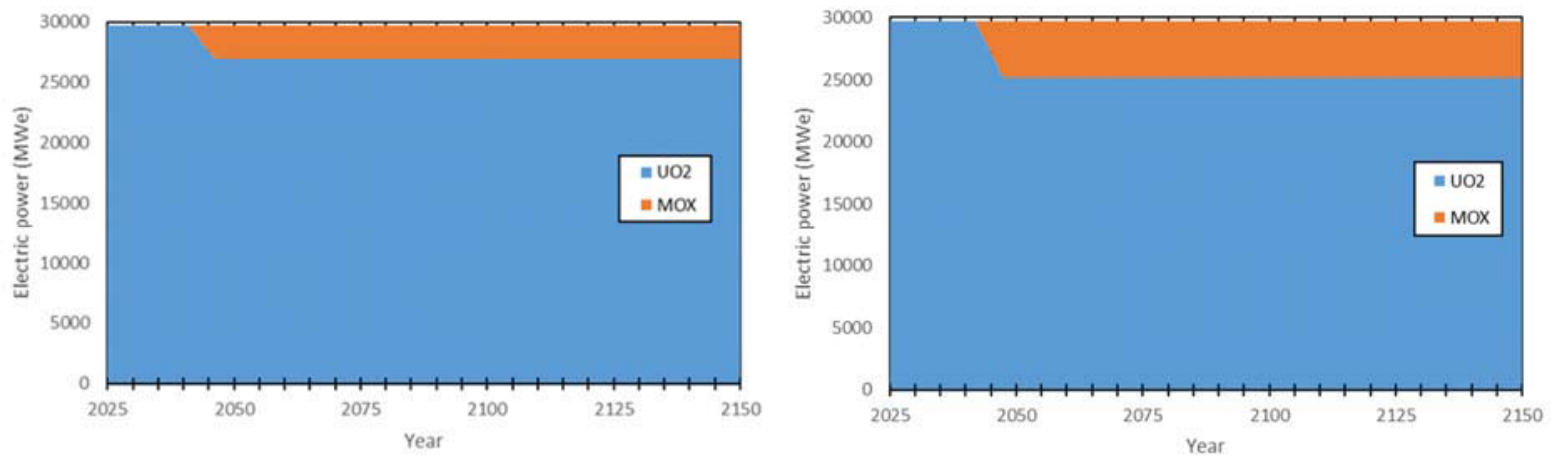

Figure 4. Installed electric power capacity in fuel scenarios (left: current, right: FORSETI).

\subsection{Results of fuel-cycle simulation}

The required weights of natural uranium are shown in Figure 5. By using the FORSETI concept, the amount of natural uranium increases. FORSETI-UO $\mathrm{U}_{2}$ fuels uses HALEU while keeping the discharge exposure at the same level as conventional $\mathrm{UO}_{2}$ fuels, therefore, the composition rate of ${ }^{235} \mathrm{U}$ in the spent-FORSETI$\mathrm{UO}_{2}$ fuels is larger than that in the current-design-spent- $\mathrm{UO}_{2}$ fuels. In order to efficiently use the surplus ${ }^{235} \mathrm{U}$, it is necessary to consider the use of the surplus reprocessed uranium to re-enrich $\mathrm{UO}_{2}$ fuels or re-use as mother material of MOX fuels as in the REMIX concept (Ref. 13). The fuel-cycle cost must be considered in the future works, however, the backend-cycle costs including partitioning and transmutation (P\&T) systems such as ADS becomes smaller. In other words, the frontend cost will increase by adopting the FORSETI concepts but total fuel-cycle cost may not incur. On the other hand, using MOX fuels in the FORSETI scenario have larger impact than that current-scenario, because, the fabrication capacity of MOX fuels will increase in the FORSETI scenario.

The amounts of TRU in the final disposal plant and in the spent-fuels are shown in Figure 6. The FORSETI concept reduces roughly $30 \%$ production of TRU from the LWRs. This is because the FORSETI concept 
1) reduces the production of TRU from the $\mathrm{UO}_{2}$ and $\mathrm{MOX}$ fuels, and 2) increases the fission rate of ${ }^{239} \mathrm{Pu}$ in the MOX fuels since the ${ }^{239} \mathrm{Pu}$ composition ratio is increased by using the concept.

The radio-heating fractions of radioactive waste are shown in Figure 7. The radio heating is mainly caused by ${ }^{90} \mathrm{Y},{ }^{137} \mathrm{Cs},{ }^{137 \mathrm{~m}} \mathrm{Ba},{ }^{238} \mathrm{Pu},{ }^{244} \mathrm{Cm}$ and ${ }^{241} \mathrm{Am}$. It is not realistic to reduce or control the production of FPs, however, the production of radio-heating TRU can be suppressed by using the FORSETI concept. As shown in Figure 7, the radio-heating fraction of radioactive waste in the FORSETI-scenario is about $10 \%$ less than that in the current-scenario. After stored for a long time, the impact of FORSETI concept becomes larger because ${ }^{238} \mathrm{Pu}$ and ${ }^{241} \mathrm{Am}$ remain the high radio-heating fraction for a long time. Especially, ${ }^{241} \mathrm{Am}$ has largest impact to radio-heating fraction of radioactive waste because it has a half-life-time of ${ }^{241} \mathrm{Am}$ of 432.6 years.

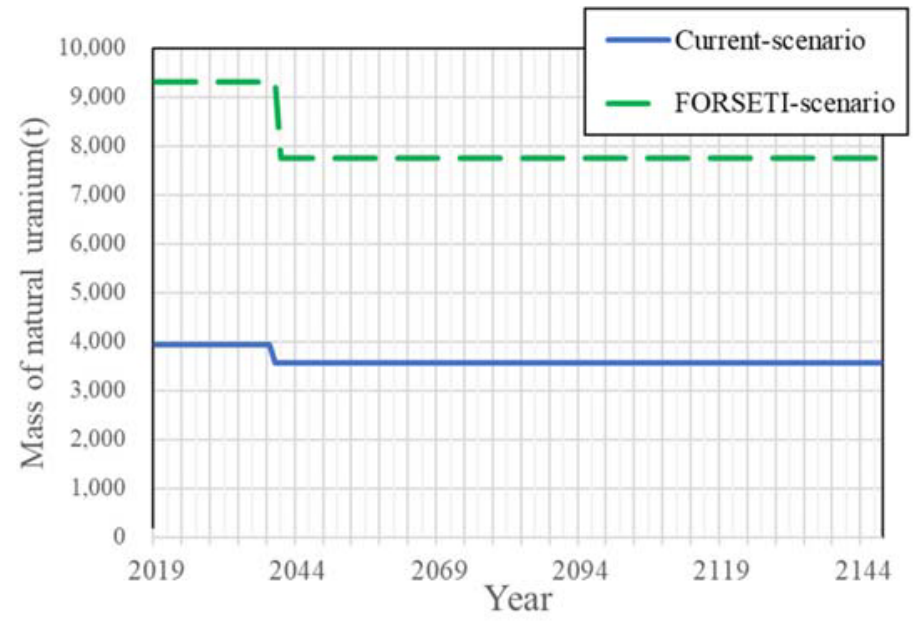

Figure 5. Natural uranium demand.

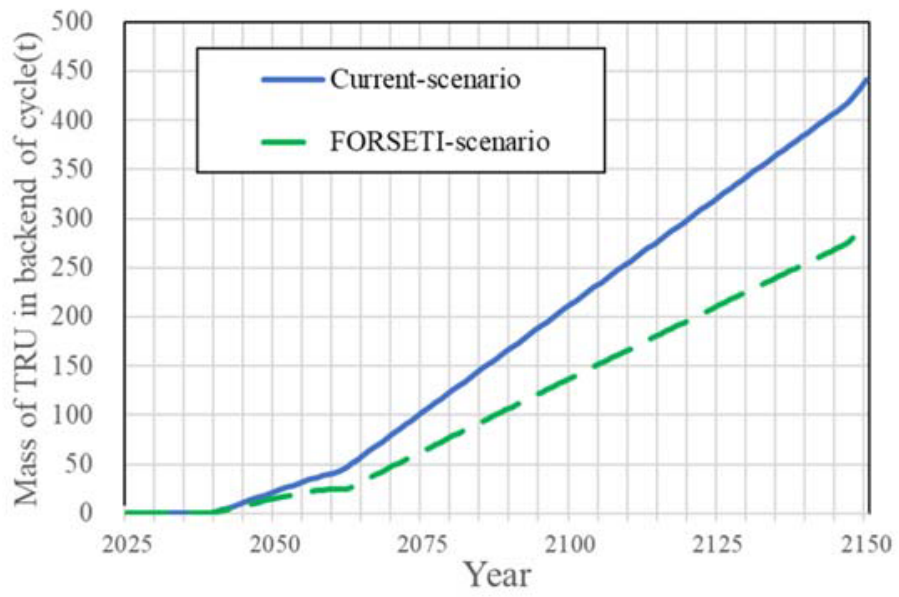

Figure 6. Mass of TRU in backend of fuel-cycle. 

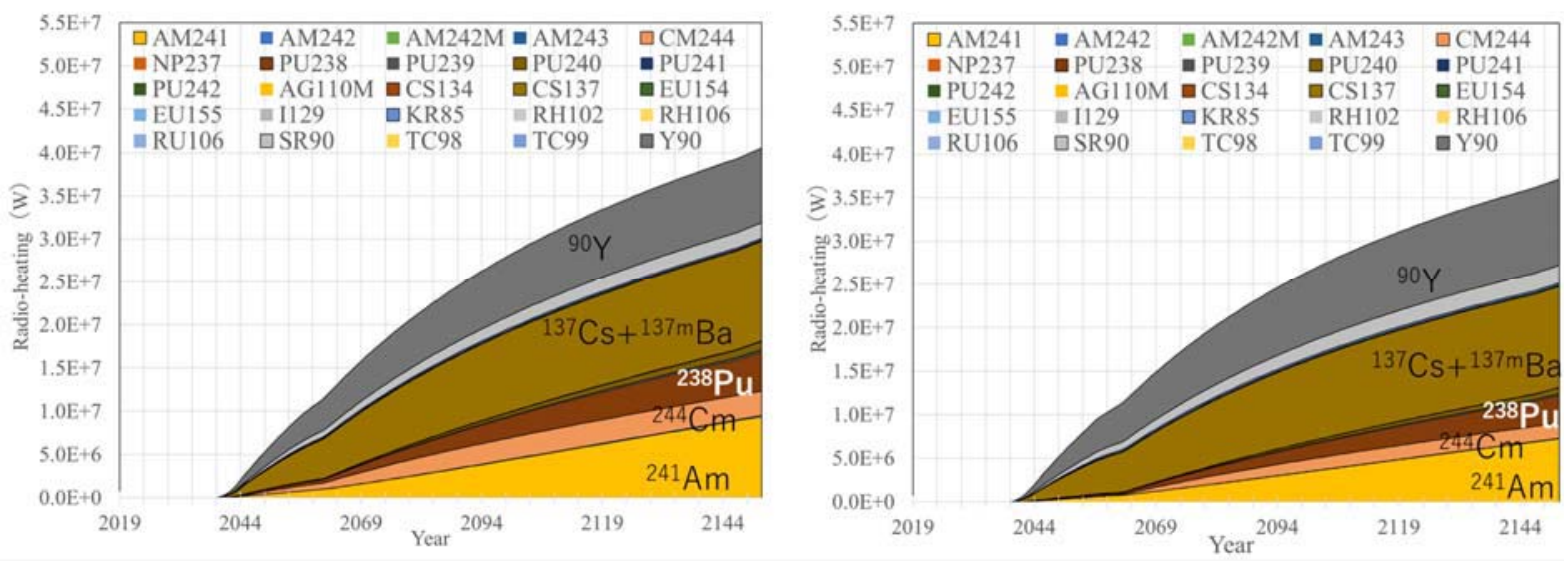

Figure 7. Radio-heating fraction fractions of radioactive waste (left: current, right: FORSETI).

\section{CONCLUSIONS}

We have investigated the fuel-cycle scenario of the FORSETI concept with ATRUNCYS code. The FORSETI concept is beneficial since it reduces the production of TRU and the radio-heating fraction of radioactive waste not only in the core but also throughout the nuclear-fuel cycle. It is worth noticing that the FORSETI concept can be applicable to the existing LWRs without major modifications to the fuels and cores.

In the current paper, the reprocessing uranium was assumed to be unused, however, by using the reprocessed uranium, further reduction of environmental loading becomes possible. In the future works, the utilization of the reprocessed uranium from spent-FORSETI-UO ${ }_{2}$, multi-recycle scenario, the impact for fuel-cycle cost by using the FORSETI concepts will be considered. In terms of the fuel-cycle cost, it is important to compare the increased frontend-cycle cost and the decreased backend-cycle cost.

\section{ACKNOWLEDGMENTS}

This study is being performed under the contract with Ministry of Education, Culture, Sports, Science, and Technology (MEXT) "MEXT nuclear system research and development Program."

\section{REFERENCES}

1. “Technology Roadmap Nuclear Energy 2015 edition,” IEA/NEA Report 2015, (2015).

2. K. Nishihara, "Data for Estimating Potential Radiotoxicity of Spent Nuclear Fuel," JAEA-Data/Code 2010-012, (2010).

3. "Accelerator-driven Systems (ADS) and Fast Reactor (FR) in Advanced Fuel Cycle A comparative study," OECD-NEA Report 2002, (2002).

4. "Technology and Components of Accelerator-Driven Systems," NEA/NSC/R (2017)2, (2017).

5. S. Wada, et al., "Conceptual Design of Fuel Cycle based on Light-Water-Reactor with Surplus Enriched Uranium for TRU-production Inhibition," Proceedings of PBNC2018, Pages 303-307, San Francisco, CA, Sep. 30- Oct. 4, 2018.

6. S. Wada, et al., "MOX fuels to Reduce TRU nuclides in Light-Water-Reactors," Proceedings of ICAPP 2019, 086, Juan-Les-Pins, France, MAY 12-15, 2019.

7. S. Wada, et al., "Nuclear Fuel Cycle Simulation Code; ATRUNCYS," Proceedings of PHYSOR2018, Pages 2288-2295, Cancun, Q.R., Mexico, Apr. 22-26, 2018. 
8. A. G. Croff, "ORIGEN2: A Versatile Computer Code for Calculating the Nuclide Compositions and Characteristics of Nuclear Materials," Nucle. Technol., 62, Page 335 (1983).

9. K. Okumura, et al., "A Set of ORIGEN2 cross section libraries based on JENDL-4.0; ORLIBJ40," JAEA-Data/Code 2012-032, (2012).

10. K. Okumura, et al., "Validation of a Continuous-Energy Monte Carlo Burn-up Code MVP-BURN and Application to Analysis of Post Irradiation Experiment", J. Nucle. Sci. Technol., 37, 128 (2000).

11. K. Shibata, et al., "JENDL-4.0: A New Library for Nuclear Science and Engineering," J. Nucl. Sci. Technol., 48(1), 1-30 (2011).

12. "Reprocessing establishment, reprocessing business change permission application revise," https://www.nsr.go.jp/data/000227290.pdf, (2018), (in Japanese).

13. Yu. S. Fedorov, et al., "Multiple Recycle of REMIX Fuel Based on Reprocessed Uranium and Plutonium Mixture in Thermal Reactors," Proceedings of GLOBAL 2013, Salt Lake City, Utah, Sep. 29- Oct 3, 2013. 